\title{
Novas Espécies do Gênero Dysonia
}

(Orthoptera-Phaneropteridae)

S. DE TOLEDO PIZA

Escola Superior de Agricultura "Luiz.de Queiroz"

Universidade de S. Paulo

\section{INDICE}

Dysonia ypsilon sp. n. ...........76

Dysonia ocraceithorax sp. n. ....... 77

Dysonia affinis sp. n. $\ldots \ldots \ldots \ldots \ldots \ldots 78$

Dysonia ornata sp. n. ........... 79

Dysonia dentatithorax $\ldots \ldots \ldots \ldots \ldots \ldots 8$ 
Dysonia ypsilon sp. n. (Fig. 1)

Mas. Pallide-virescens, discrete nigro-maculatus. Frons dilute castaneo-virescens ad latera densior, puncturata, postice utrinque a linea nigra infra oculos demarcata. Fastigium verticis cum fastigio frontis haud contiguum. Spina verticis triangularis, acuta, lateraliter atro-lineata. Os atrum. Pronotum obliquum, laeve,sellaeforme, margine postico rotundato, interrupte nigro-lineato, postice in medio modice elevatum, utrinque ad angulos prominenter triangulariter-compressum et sparsim minute nigro-punctatum, lobis deflexis a spina basali coxarum anticarum ad exteriorem incurvis, marginibus late rotundato-lobatis. Elytra alis breviora, apice paulo dilatata et nigro-punctata, margine suturali ordinatim nigro-maculato et inter maculas minute punctato, margine antico et vena radiali ad basin nigro-punctatis, disco maculis nigris parvulis sparsis necnon macula magna tri-ramosa litteram $\mathrm{Y}$ imitante, ramis duobus ad marginem suturalem orientibus, ramo tertio dimidiam latitudinem elytrorum attingente, trientem apicalem occupante, ornato. Pars anterior alarum prope apicem obliquiter nigro-fasciata. Pectus, coxae I et pars ventralis coxarum II et III nigra. Thorax ad latera partim nigrus, partim nigro-punctatus. Pedes antici trochanteribus subtus ac femoribus in parte basali colore frontis, tibiis pone partem basilarem dilatatam nigro-fasciatis, ad apicem lateraliter nigro-signatis, tarsis, articuło ultimo excepto, lateraliter et inferne nigris, unguiculis apice nigris. Pedes intermedii trochanteribus inferne nigris, femoribus in medio late obliquiter nigro-vittatis, superne ad apicem nigro-signatis, subtus ad marginem anticum dentibus 4 armatis, primo parvulissimo spiniformi in fascia mediana nigra sito, a secundo versus apicem crescentibus, triangulariter dilatatis, ultimo bilobulato, tibiis superne ad basin nigro-punctatis, pone medium nigro-fasciatis, ad apicem nigr?signatis, superne ante medium dentibus 3 triangularibus utroque margine armatis, prope apicem intus tantum dente triangulari ac lobo rotundato praeditis. Pedes postici trochanteribus subtus nigris, femoribus ad basin et apicem nigris necnon fascia nigra pone partem ampliatam ornatis, inferne utrinque spinis parvis, margine interno lobo magno intus nigro ad apicem instructis, (margine externo ?), tibiis superne lobis 2-2, $1-0,2-3,3-3,2-3$ armatis necnon fascia nigra in medio, altera praeapicali ornatis, inferne parte basali et parte ventrali inho- 
rum basalium nigris, medio et parte praeapicali ut superne. Segmenta abdominalia ventralia nigra. Lamina subgenitalis profunde fissa, basi nigra, lobis latis, pilosis, inferne carinulatis, stylis brevibus, compressis, praeditis. Cerci crassi, conici, granulati, pilosi, apice bi-ramosi, ramo inferiore recto, apice nigro, ramo superiore adunco, supra ramum inferiorem incurvo, dimidia parte apicali nigro.

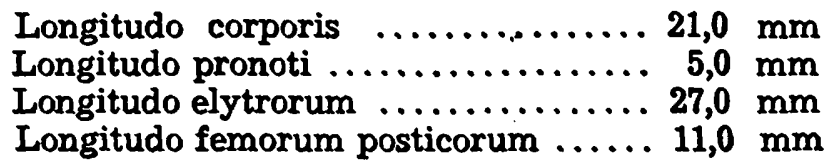

Patria : ?

Col. : ?

Tipos: Dois machos com o N. 22131 pertencentes ao Departamento de Zoologia, atualmente no Laboratório do A.

Nota: Segundo informaçōes gentilmente prestadas pelo Dr. F. Lane, por intermédio do Dr. Hélio F. de A. Camargo, os tipos fazem parte de um lote de insetos adquiridos por volta de 1934 de uma senhịora que residia em Mogi das Cruzes, E. de São Paulo.

Dysonia ocraceithorax sp. n. (Fig. 2)

Mas. Pallide virescens, nigro-punctatus et irregulariter fusco-lavatus. Pars anterior capitis omnino nigra, puncturata. Occiput vertexque ocracei. Articuli antennarum I et II ocracei, parce nigro-signati, articuli reliqui omnino fere nigri. Ocuif sat prominuli, ocracei. Spina verticis brevis, procurva, lateraliter nigra. Fastigium verticis cum fastigio frontis haud contiguum. Pronotum ocraceum, disco fortiter obliquo, margine antico in medio vix prominulo, granulis prominentibus nonnullis praedito, parte posteriore dense nigro-granulata, in medio lobulato-elevata, utrinque ad angulos compresso-elevata, lobis deflexis fortiter reflexis, marginibus lobulatis et parce nigro-granulatis. Elytra pallide viridia, irregulariter fusco-maculata et lavata, parte dorsali elytri sinistri-vena plicata precipuenigro-granulata, venis radialibus et dimidia parte apicali venae costalis nigro-granulatis, apice lobulatim ampliata. Alae 
elytris longiores, parte anteriore ad apicem obliquiter nigrovittata, campo ulnari (apud nom. Brunneri) ad basin venis transversis parallelis duabus praedito. Pectus coxaeque nigrae. Pedes antici trochanteribus subtus nigris, femoribus parte basali nigris, superne in medio lobo valido, inferne intus lobo elongato, extus dentibus parvis duobus praeapicalibus instructis, tibiis pone partem basalem ampliatam obliquiter anguste nigro-fasciatis, apice late nigro-fasciatis, tarsis-parte apicali articuli ultimi excepta-nigris. Pedes medii trochanteribus inferne nigris, femoribus in medio nigro-cinctis, inferne ad marginem anticum spinis parvis 2 prope medium, dentibus 2-3 crescentibus prope apicem armatis, tibiis in medio anguste, ad apicem late nigro-cinctis, superne ad basin teretibus, dehinc usque ad medium utrinque 3 vel 4-lobatis, ultra medium inermibus vel intus tantum bidentatis, tarsis ut in pedibus anticis ornatis. (Pedes postici carentes). Abdomen superne et inferne nigrum. Lamina subgenitalis basi nigra, apice profunde fissa, lobis ventraliter indistincte carinulatis, puncturatis, pilosis, stylis parvulis, compressis, armatis. Cerci breves, crassi, rotundati, granulati, ramis spiniformibus 2 terminati, acutis, incurvis, apice nigris, superiore quam inferior breviore.

Longitudo corporis ............ 18,5 mm

Longitudo pronoti ............. 5,5 $\mathrm{mm}$

Longitudo elytrorum ........... 27,0 mm

Latitudo elytrorum in medio ...... $5,5 \mathrm{~mm}$

Latitudo elytrorum ad lobum apic. .. $7,0 \mathrm{~mm}$

Longitudo femorum anticorum .... $4,0 \mathrm{~mm}$

Longitudo femorum intermediorum .. $6,0 \mathrm{~mm}$

Patria : Ypiranga, S. Paulo.

Col. : Lüderwaldt, XI - 1909.

Tipo: Um macho com o N. 14894 pertencente ao Departamento de Zoologia, presentemente na coleção do $\mathrm{A}$.

Dysonia affinis sp. n. (Fig. 3)

Mas. Precedenti similis sed differt fronte pronotoque plus minusve colore corporis, oculis castaneo-badiis, lobiis deflexis pronoti perpendicularibus, marginibus vix reflexis, elytris disco haud maculato, nigro-punctato, margine suturali maculis ni- 
gris ordinatis ornato, campo ulnari alarum ad basin venis transversis parallelis 5 praedito, parte basali femorum anticorum dilute castaneo-rufa, parte apicali longiore et angustiore superne ad apicem haud nigro-signata, tibiis intermediis superne lobis dentiformibus magis acuminatis, parte apicali haud nigro-signata, cercis basi gracilioribus atque brevioribus, spinis terminalibus incurvis valde longioribus. Pedes postici (in specie precedenti carentes) femoribus superne, praeter punctos nigros, macula nigra longa ad basin et fascia lata nigra ultra medium ornatis, inferne marginibus dentatis, ad partem apicalem lobo magno, dentato, nigro, utrinque praeditis, tibiis superne ad basin nigro-punctatis necnon fasciis 3 nigris remotis ornatis, marginibus irregulariter acute lobulato-dentais, inferne et lateraliter magna parte nigro-ornatis.

Longitudo corporis $\ldots \ldots \ldots \ldots \ldots \ldots 20,5 \mathrm{~mm}$

Longitudo pronoti $\ldots \ldots \ldots \ldots \ldots \ldots, 4,0 \mathrm{~mm}$

Longitudo elytrorum ........... 25,0 mm

Longitudo femorum anticorum ...., 4,0 mm

Longitudo femorum posticorum .... $11,0 \mathrm{~mm}$

Pátria : Alto da Serra (Paranapiacaba), E. de S. Paulo.

Col. : Spitz, 1925.

Tipo: Um macho pertencente ao Departamento de Zoologia, presentemente na coleção do $A$.

r. Dysonia ornata.sp. n. (Fig. 4)

Mas. Virescens, omnino nigro-ornatus. Caput lutescens, fronte nitida, superne atro-fasciata, fastigio lateraliter nigro, oculis magnis, castaneo-nitidis, vertice haud spinoso, longitudinaliter late ferrugineo-nigro 4-vittato, fastigio sulcato, postice nigro-signato, antice cum fastigio frontis subcontiguo. Pronotum lutescens, nitidum, maculis magnis nigro-nitidis ornatum, angulis humeralibus haud elevatis, lobis deflexis brevibus, obtiqquis sed haud reflexis, postice gibberosis, marginibus rotundatis, integris. Elytra pallide viridia, prominenter reticulata, apice vix ampliato, obliquiter truncato, varie nigro-ornatai câmpo dorsali amplè nigro-plagiato, vena plicata totà fere nigra, venis radialibus luteis. Alae apice : pigro-maculatae necnon maculis nigris seriatis prope marginem anticum ornatae. Sterna nigro-nitida. Pleurae ample nigro-ornatae. Pedes 
antici trochanteribus subtus nigro-nitidis, femoribus ad basin fascia nigro-nitida inferne latissima, superne angusta, antice interrupta ornatis, superne prope apicem macula parva, subtus ad marginem anticum dentibus triangularibus acutis 2 armatis, tibiis medio et apice late nigro-fasciatis, ad basin inferne et antice nigro-signatis, membranis foraminarum nigris, tarsis-parte superiore excepta-nigris. Pedes intermedii femoribus in medio latissime nigro-cinctis, superne prope apicem macula nigra ornatis, inferne ad marginem anticum triangulariter bidentatis, tibiis et tarsis ut in pedibus anticis ornatis. Pedes postici trochanteribus omnino fere nigris, femoribus basi nigris necnon fasciis nigris 3 ornatis, prima lata, extus interrupta, cum nigro basis superne connecta, ad marginem externum dentibus 5 vel 6 versus apicem crescentibus, lobo magno horizontali, basi acute triangulariter dentato, apice obtuse bidentato, superne et inferne ferrugineo, armatis, ad marginem internum dentibus acutis 2 ac lobo angusto bidentato praeditis, superne ad lobos ample ferrugineo-ornatis, tibiis late nigro 3-fasciatis, apice nigris, basi nigro-signatis, superne utrinque acutissime pluridentatis, tarsis ut in pedibus precedentibus ornatis. Segmenta abdominalia ventralia in medio castaneonigro signata. Lamina subgenitalis bipartita, postice quam antice angustior. Cerci crassi, subcylindrici, biramosi, ramis nigris, interno dentiformi, externo elongato, excurvo, inferne nigri, minutissime granulati, pilosi.

Longitudo corporis $\ldots \ldots \ldots \ldots \ldots \ldots 14,0 \mathrm{~mm}$

Longitudo elytrorum ............. $28,0 \mathrm{~mm}$

Latitudo elytrorum ad apicem ...... 5,5 $\mathrm{mm}$

Longitudo femorum anticorum ..... 4,0 mm

Longitudo femorum posticorum ..... 14,0 mm

Pátria : Salesópolis, Boracéia, E. de S. Paulo.

Col.: Travassos Filho, Braz, Rabelo \& Bohermann, de 6 a 11 de Março, de 1948.

Tipo: Um macho pertencente ao Departamento de Zoologia, atualmente com o A. 
Dysonia dentatithorax sp n. (Fig. 5)

Mas. Viridis, nigro-ornatus. Frons-fastigio excepto-nigra, dense punctato-impressa, breve-pilosa. Articulus antennarum primus extus niger, articuli coeteri nigri, partim albo-signati. Spina verticis valida, compressa, ad apicem truncata, utrinque et antice nigra, postice nigro-granulata. Fastigium verticis parvum, dentiforme, obtusum, haud sulcatum, a fastigio frontis valde remotum. Pronotum disco antice seriatim nigro-granulato, in medio granulis nigris sparsis obtecto, postice in detem parvum plicato, angulis humeralibus compresso-elevatis, validis, superne dense irregulariter nigro granulatis, inferne granulis minoribus nonnullis praeditis, margine supero fortiter tuberculato-dentato, lobis lateralibus reflexis, marginibus omnino tuberculato-dentatis. Elytra viridia, lobo apicali magno, densiore, campo dorsali granulis nigris compluribus, vena stridulanti granulis nonnulis majoribus necnon macula nigra ad extremitatem suturalem praedita, margine postico maculis nigris 3 , prima ad finem campi dorsalis, secunda in medio, ultima ante lobum apicalem praedito, margine antico granulis nigris partim ornato, disco rarissime minutissime nigrogranulato, venis radialibus, anteriore precipue, nigro-granulatis, maculis nigris parvis nonnullis secundum venam radialem posteriorem ornato, margine antico seriatim nigro-granulato. Pars anterior alarum ad apicem obliquiter nigro-fasciata. Mesothorax et metathorax ad latera omnino fere nigri, granulati. Sterna nigra. Pedes breve-pilosi. Pedes I: coxae ac trochanteres nigri, femora compressa, tertia parte apicali viridi, punctis nigris nonnollis ornata, parte reliqua nigro-ferruginea, granulosa, superne lobo magno tuberiformi praedita, inferne ad marginem posticum cristato-lobata, tibiae in medio obliquiter nigro-anulatae, apice late nigrae, superne ad partem distalem dilatationis basilaris antice dentatae, inferne utrinque nigro-spinulosae; tarsi-parte superiore excepta-nigri. Pedes II: coxae ac trochanteres partim nigri, partim nigro-punctati; femora in medio nigro-anulata, superne ad basin dilute ferruginea, ferrugineo-granulata, parte apicali granulis nigris nonnullis praedita, inferne ad dimidiam partem apicalem marginis antici dentibus acutis 4 lobum angustum designantibus necnon dentibus 1-2 liberis instructa; tibiae superne ad basin minute nigro-maculatae, in medio obliquiter nigro-anulatae, apice nigrae, parte basali utrinque 3-dentatae, parte apicali postice tan- 
tum 2-dentatae, dente ultimo lobiformi; tarsi ut in pedibus anticis. Pedes III : trochanteres partim nigro-granulati; femora basi nigra, superne plus minusve nigro vel ferrugineo-granulata, ad partem basalem macula longa nigra ornata, prope medium superne et inferne nigro-maculata, prope apicem nigrofasciata, apice nigra, inferne ad apicem lobo magno, dentato, granuloso, nigro, utrinque armata, dentibus parvulis nonnullis ad margines necnon dente majore prope lobum posteriorem instructa; tibiae ad apicem nigrae, ad tertiam partem apicalem nigro-fasciatae, superne ad basin maculis minimis nigris nonnullis, lobis magnis dentatis nigro-granulatis 2 utrinque praeditae post quos dente 1 ad marginem internum et 3 utrinque precedentibus similibus utroque margine armatae, inferne ad dimidiam partem basalem nigrae; tarsi anterioribus simili. Segmenta abdominalia ventralia-linea lutea mediana excepta-nigra. Lamina subgenitalis omnino fere nigra. Cerci crassi, dense granulati, apice spinis 2 nigris, curvis, armati, interna quam externa majore et ad basin triangulariter ampliata.

Longitudo corporis $\ldots \ldots \ldots \ldots \ldots \ldots$ 17,5 mm

Longitudo pronoti $\ldots \ldots \ldots \ldots \ldots \ldots \ldots, 6, \mathbf{6 , 2} \mathrm{mm}$

Longitudo elytrorum ........... 29,0 mm

Longitudo femorum anticorum ..... 5,0 $\mathrm{mm}$

Longitudo femorum posticorum ..... 12,0 $\mathrm{mm}$

Pátria : Campos do Jordão, E. de São Paulo.

Tipo: Um macho.

Parátipos: Dois machos da mesma procedência, semelhantes ao tipo. 

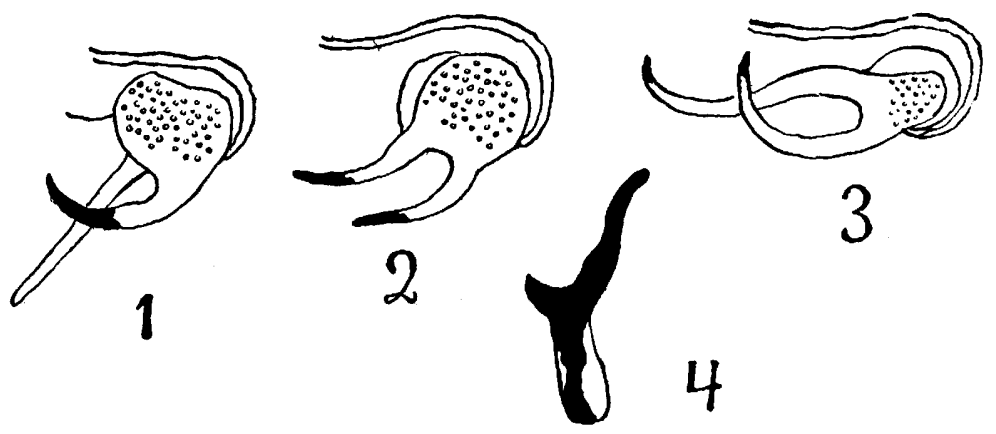

(Fig. 1) - Cercus de Dysonia ypsilon sp. $n$.

(Fig. 2) - Cercus de Dysonia ocraceithorax sp. n.

(Fig. 3) - Cercus de Dysonia affinis sp. n.

(Fig. 4) - Cercus de Dysonia ornata sp. n.

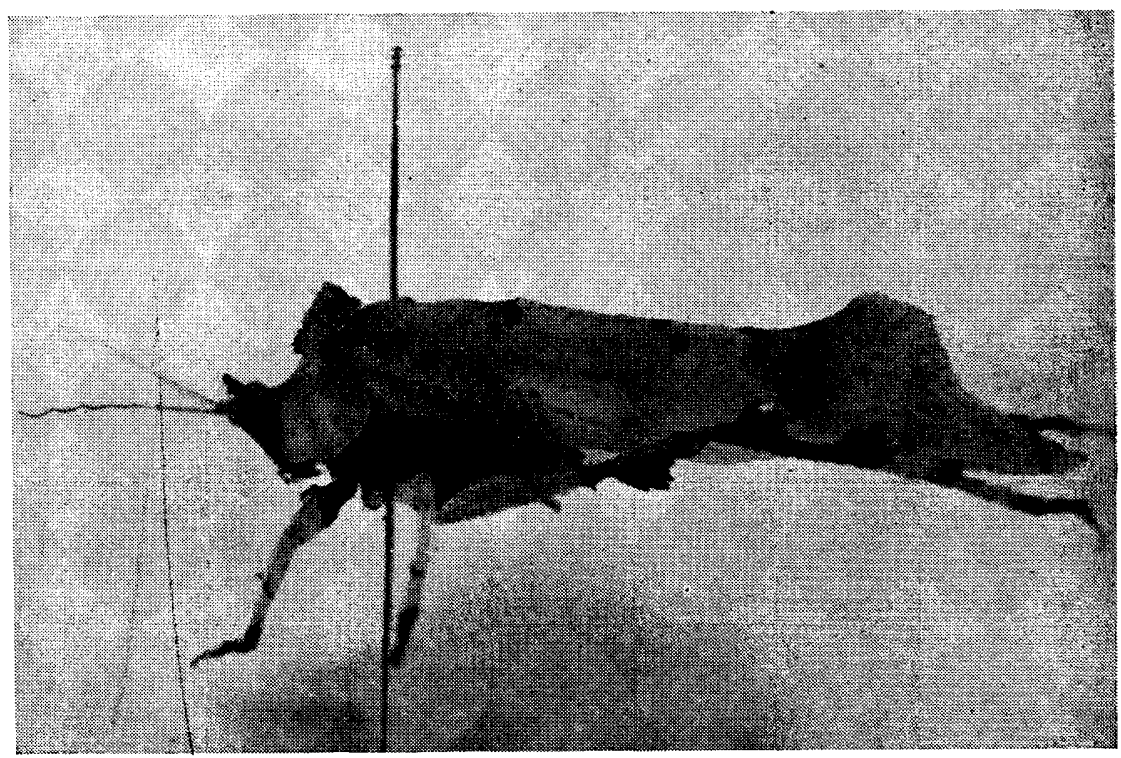

(Fig. 5) - Dysonia dentatithorax sp. n. (macho) 
